\title{
Special Considerations in Air Travel for Pregnant Women
}

Zahra Pahlavani Sheikhi ${ }^{*}$

${ }^{1}$ Pregnancy Health Research Center, Zahedan University of Medical Sciences, Zahedan, Iran

Corresponding Author: Zahra Pahlavani Sheikhi, M.Sc., Pregnancy Health Research Center, Zahedan University of Medical Sciences, Zahedan, Iran. Phone \& Fax: +98 5433442481,Email: Pahlavani_86@yahoo.com

Received April 12, 2017; Accepted May 1, 2017; Online Published May 31, 2017

Citation: Pahlavani Sheikhi Z. Special considerations in air travel for pregnant women. Int J Travel Med Glob Health. 2017;5(2):69. doi:10.15171/ ijtmgh.2017.13.

\section{Dear Editor}

International air travel has increased during the recent century, and the number of pregnant women who travel internationally by air is on the rise. Most pregnant women are able to fly safely, but general considerations must be taken into account. Prior to traveling, pregnant women should be assessed for gestational age, fetus and placenta status, blood group and Rh status by laboratory evaluation or with diagnostic ultrasound imaging. The Center for Disease Control and Prevention (CDC) recommends that pregnant women travelers carry a copy of their medical records with them on their trip. ${ }^{1}$

The latest recommendation of the ACOG indicates that occasional travel by air during pregnancy is safe. Specifically, occasional air travel by women with a singleton pregnancy can be done until 36 weeks gestation. Women with an uncomplicated multiple pregnancy are allowed to fly up to the end of the 32nd week. As emergencies usually happen in the first and third trimesters, the safest time to travel is probably the middle of the pregnancy, between 14-18 weeks. ${ }^{2,3}$

Almost all women with a normal pregnancy can travel without limitation up to 28 weeks, but there are few contraindications for air travel, including obstetric complications, severe anemia $(\mathrm{Hb}<7.5 \mathrm{~g} / \mathrm{dL})$, recent hemorrhage, sickle cell anemia, acute otitis media and sinusitis, uncontrolled cardiac or respiratory disease, and a post-operative condition as with recent gastrointestinal surgery. ${ }^{3}$

Although air travel is safe, there are specific risks during pregnancy. The incidences of miscarriage and preterm birth are greater among flight attendants than the general population. Exposure to cosmic radiation is not hazardous to the fetus for the occasional pregnant air traveler. One other concern is venous thromboembolism for which flight duration is a key factor. Air travel of more than 4 hours at a time may increase the risk of venous thromboembolism, but this is a weak risk factor. Immobility during long flights can lead to such a condition. ${ }^{4,5}$
There are some general suggestions for the pregnant traveler to minimize the risk of an adverse outcome related to air travel during pregnancy. Before planning to travel, women should check the airline's policy about air travel during pregnancy. The traveler's seat belt should be closed during a flight, and unnecessary traffic should be avoided. Because of the necessity of take occasional walks, pregnant women should have an aisle seat to facilitate movement. Women should drink plenty of fluids to avoid dehydration. Furthermore, the pregnant traveler should avoid gassy foods and drinks preflight. ${ }^{1-3}$

\section{Conflict of Interest Disclosures}

None.

\section{Ethical Approval}

Not applicable.

\section{Funding/Support}

None.

\section{Acknowledgements}

The authors express their thanks to the staff of the Pregnancy Health Research Center, Zahedan University of Medical Science.

\section{References}

1. Centre for Disease Control and Prevention. Advising Travelers with Specific Needs. In: Yellow book. Pregnant Travelers; 2016.

2. ACOG Committee on Obstetric Practice. ACOG Committee Opinion 443: Air Travel during pregnancy. Obstet Gynecol. 2009;114(4):954-955. doi:10.1097/AOG.0b013e3181bd1325

3. Royal College of Obstetricians and Gynaecologists. Air travel and pregnancy. Scientific Impact Paper No1. https://www.rcog.org.uk/ en/guidelines-research-services/guidelines/sip1/. Published 2013.

4. Hezelgrave NL, Whitty CJM, Shennan AH, Chappell LC. Advising on travel during pregnancy. BMJ. 2011;342:d2506. doi:10.1136/ bmj.d2506.

5. Mohan AR, Nelson-Piercy C. Air travel in pregnancy. Curr Obstet Gynaecol. 2014;24(11):345-346. 